UPPSALA UNIVERSITET
Working Paper 2009:3

Department of Economics

Optimal nonlinear redistributive taxation and public good provision in an economy with Veblen effects

Luca Micheletto 
Department of Economics

Working paper 2009:3

Uppsala University

March 2009

P.O. Box 513

ISSN $1653-6975$

SE-751 20 Uppsala

Sweden

Fax: $+{ }_{4} 6184711478$

\author{
OPTIMAL NONLINEAR REDISTRIBUTIVE TAXATION \\ AND PUBLIC GOOD PROVISION IN AN ECONOMY WITH \\ VEBLEN EFFECTS
}

LuCA Micheletto

Papers in the Working Paper Series are published on internet in PDF formats.

Download from http://www.nek.uu.se or from S-WoPEC http://swopec.hhs.se/uunewp/ 


\title{
Optimal nonlinear redistributive taxation and public good provision in an economy with Veblen effects*
}

\author{
Luca Micheletto ${ }^{\dagger}$
}

\begin{abstract}
This paper deals with the consequences of the assumption of negatively interdependent preferences for the shape of the optimal nonlinear income tax and the efficient level of public good provision in a setting where the policy maker maximizes an inequality averse social welfare function and the agents' market ability is private information. The analysis points out that the terms added in the tax formulas due to the presence of Veblen effects might justify a reduction in the optimal marginal tax rates faced by the different individuals. Also, the desirability of negative marginal tax rates cannot be ruled out. With respect to the issue of the optimal level of public good provision, we derive a modified Samuelson rule and highlight the fact that the Veblen-based part of the formula might require to distort downwards the efficient level of public good provision.
\end{abstract}

Keywords: optimal nonlinear income taxation; modified Samuelson rule; Veblen effects

JEL Classification: H21; H23; H41

${ }^{*}$ I would like to thank two anonymous referees for their valuable suggestions. I would also like to thank Spencer Bastani, Sören Blomquist, Luciano Greco and Alessandro Petretto for their comments on an earlier draft. The usual disclaimer applies.

${ }^{\dagger}$ Faculty of Law, University of Milan, I-20122 Milan, Italy, and Econpubblica, L. Bocconi University, I-20136 Milan, Italy. E-mail address: luca.micheletto@unibocconi.it 


\section{Introduction}

This paper deals with the consequences of the assumption of negatively interdependent preferences for the shape of the optimal nonlinear income tax and the efficient level of public good provision in a setting where the policy maker maximizes an inequality averse social welfare function and the agents' market ability is private information.

At the end of the nineteenth century, Thorsten Veblen (1899) criticized classical economics stressing its failure to recognize that in affluent societies the "dominant incentive" for owning property was to demonstrate "pecuniary success" and thereby to obtain "invidious distinction". ${ }^{1}$ In perhaps the best known aspect of his theory, he maintained that people seek "invidious distinction" by demonstrating their wealth through the behavior of "conspicuous consumption" and "conspicuous leisure".2 Even if the choice between the two is merely a question of advertising expediency, Veblen also thought that over time the trend of development would have heightened the utility of conspicuous consumption as compared with leisure. ${ }^{3}$ Despite the fact that Veblen's view of social preferences was soon eclipsed by the simpler neoclassical theory of consumer behavior, his basic insight has later been reformulated in distinct ways to capture the idea that one's well-being is determined not only by the intrinsic utility of own material consumption, but also by one's relative standing in the society or in his peer group. ${ }^{4}$ Among the most concerted effort to incorporate relative preferences into mainstream consumer theory, Duesenberry's (1949) relative income hypothesis contends that, when one person increases his income, he imposes utility losses on others. However, as suggested by Runciman (1966), the evidence seems to be that people are mainly bothered about the income of those close to them in the earning distribution and do not suffer greatly from the riches of the rich (or of the poor), unless they happen to be nearly rich (poor) themselves. Moreover, as recently confirmed by Bowles and Park (2005), it also seems that people tend to refer upwards, to a richer reference group, rather than downwards, seeking social distance from a poorer group.

In the public finance literature the tax consequences of these kinds of

\footnotetext{
${ }^{1}$ Even if a less well-known contribution, the importance of relative standing had already been discussed some decades earlier by Rae (1834).

${ }^{2}$ By the latter, Veblen meant behavior that demonstrates one's abstention from work. Conspicuous consumption refers instead to the consumption of goods that are manifestly expensive for reasons other than the function they serve.

${ }^{3}$ Leisure tends to have a more ambiguous symbolic significance when compared with consumption. As society becomes more fragmented and transient, it becomes more important to display wealth to strangers who may mistake conspicuous leisure for unemployment.

${ }^{4}$ See e.g. Duesenberry (1949), Galbraith (1958), Easterlin (1974), Hirsch (1976), Scitovsky (1976), Layard (1980), Frank (1985) and Schor (1998).
} 
interdependencies in individuals' utilities have been explored in contributions by, among others, Boskin and Sheshinski (1978), Oswald (1983) Seidman (1987), Persson (1995), Ireland (2001), Corneo (2002) and Balestrino (2006). However, the possibility of negative marginal tax rates in a Veblen economy seems to have been overlooked. Usually, the circumstance that people care about others' consumption, in the sense that they try to keep up with the Joneses, has been used to warrant higher marginal tax rates for the efficiency purpose of externality internalization. Intuitively, a reduction in the net return to labor effort, lowering the relative price (opportunity cost) of leisure, helps counterbalancing the tendency of people to overwork and sacrifice leisure excessively. The picture is however more complicated if one assumes that the government is relying on nonlinear income taxation to achieve some redistributive goals in a setting where agents' market ability is private information. The reason is that in such a setting the policy maker's redistributive efforts are typically thwarted by a set of binding self-selection constraints requiring that agents must be at least as well off by accepting the consumption-income bundle meant for them as by mimicking, namely choosing the bundle meant for another type of agent. ${ }^{5}$ As we will see later on, when these incentive constraints are taken into account, it is possible that, in the expressions for the optimal marginal tax rates, the sign of the term capturing the phenomenon of negative interdependent preferences is negative, contributing to lower the value of the marginal tax rates.

The key to understand this result is that a mimicker might be hurt more than the person being mimicked from a marginal increase in the wealth of the next highest income agents. If this is the case, lowering the marginal tax rate faced by the higher income agents, in order to induce them to slightly increase their pre-tax income, helps softening the self-selection constraint, allowing in this way the government to push redistribution further. Since mimickers and mimicked have the same disposable (after-tax) income but differ with respect to labor supply, it is apparent that a crucial condition to assess the desirability of lowering the marginal tax rates is whether the marginal externality caused by the wealth of the next highest income agents is increasing or decreasing with one's labor supply.

Another issue that we investigate in this paper is the appropriate level of public good provision when agents have spiteful preferences and the government pursues redistributive objectives via nonlinear income taxation. ${ }^{6}$ Prima facie it might seem straightforward that the presence of Veblen ef-

\footnotetext{
${ }^{5}$ No self-selection constraint would be binding only if the social welfare function maximized by the policy maker were such that the solution to the government's problem coincides with, or is in the neighborhood of, the laissez-faire equilibrium (which, as is well known, is incentive compatible).

${ }^{6}$ In this paper we will use the terms "Veblen effects", "negatively interdependent preferences", "spiteful preferences" and "negative tuistic preferences" as synonymous. In particular, the expression "Veblen effects" is used in a different way than the one intended
} 
fects should increase the efficient level of public good expenditure. After all, substituting public goods for private consumption involves in such a setting an additional benefit given that public goods are by definition available to everybody, whereas rival private consumption confers a utility gain to the beneficiary but at the same time imposes a negative external effects on some other persons. A cautionary note with respect to this simple way of reasoning was already expressed by $\mathrm{Ng}$ (1987) in a model where the welfare of an individual did not depend only on his absolute income but also on his relative income share. In that paper the ambiguity of the result on the optimal level of public expenditure stemmed from the circumstance that, while the presence of relative-income effects increased the external costs of private goods, it also increased their internal benefit. Due to the way that the spiteful preferences are introduced in our paper, the latter effect does not arise in the model that we are going to present. Nonetheless, a similar ambiguity of results emerges, although for different reasons, as an outcome of the analysis. In particular, after having derived a modified Samuelson rule for the optimal level of public good provision, it turns out that it is not possible to unambiguously determine the overall sign of the additional terms that appear due to the presence of Veblen effects. As it will become clear later on, it is once again the effect on the self-selection constraints, this time descending from substituting at the margin public for private consumption, which plays a crucial role to understand the nature of the results.

The plan of the paper is the following. The basic model is presented in Section 2 together with the results on the optimal marginal tax rates and the optimal level of public good provision. Section 3 considers how the results are affected assuming that the agents' spiteful preferences are "laundered" in the government's objective function. Section 4 provides a numerical example. Section 5 offers concluding remarks.

\section{The model}

The model builds on the Stiglitz (1982) discrete version of the Mirrlees (1971) optimal income taxation model. The economy is populated by individuals who can be grouped into three different types. The types differ with respect to their (inalterable and) innate (market) ability: type 1 are the least skilled agents, type 3 are the most skilled agents and type 2 represent the intermediate type. The population size is normalized to one and the proportion of persons of type $i(i=1,2,3)$ is denoted by $\pi_{i}$. The difference in ability (output produced per unit of time spent working) is reflected in the

by Leibenstein (1950) in his classical contribution. For a discussion of the circumstances under which it makes sense to distinguish between negatively interdependent preferences and spiteful preferences, see Ok and Kockesen (2000). The term tuistic preferences was first introduced by Gauthier (1986) who borrowed it from Wicksteed (1933). 
difference in unitary pre-tax wage $(w)$ paid to individuals: $w_{3}>w_{2}>w_{1}$. Two goods are produced using a linear technology which employs labor as the only input: a composite private consumption good and a public good. The producer price of the private good is normalized to unity, whereas $p_{g}$ denotes the unitary cost of production of the public good.

To capture the idea that interpersonal comparisons are relevant to determine individuals' well-being, we build on the evidence provided by Bowles and Park (2005) and assume that people compare consumption (but not leisure) and that they refer upwards, namely take decisions looking at the consumption of those above them in the earnings distribution rather than seeking social distance from lower income groups.

A simple way to model this behavior is to assume that agents have preferences described by the concave utility function $U\left(C_{i}, L_{i}, G ; C_{i+1}\right)$, where $C_{i}$ and $L_{i}$ are respectively the agent's private consumption and labor supply, $C_{i+1}$ denotes the private consumption of the next highest income agents and $G$ represents a public good consumed uniformly by all agents. Notice that for each agent the reference group is taken to be the next highest income agents. Clearly, since we are modelling spiteful preferences, it will be $\partial U\left(C_{i}, L_{i}, G ; C_{i+1}\right) / \partial C_{i+1}<0$. Since the richest agents have no reference group, to define their utility we introduce the function $\widetilde{U}\left(C_{i}, L_{i}, G\right)$ with the following properties: $\widetilde{U}\left(C_{i}, L_{i}, G\right)>U\left(C_{i}, L_{i}, G ; C_{i+1}\right)$ and $\widetilde{U}\left(C_{i}, L_{i}, G\right)=$ $U\left(C_{i}, L_{i}, G ; C_{i}\right)$.

The government knows agents' preferences and the distribution of ability in the population but can observe neither $L$ nor $w$, while it can observe their product $Y$, earned income. Thus, the government is prevented from optimizing the income distribution imposing, as it would be first best, lumpsum taxes/transfers conditioned on ability. Instead, it has at its disposal a nonlinear income tax $T(Y) .{ }^{7}$ The problem of choosing the direct tax schedule can be equivalently stated as the problem of selecting three pairs of pre-tax and disposable incomes $\left(Y_{i}, C_{i}\right), C_{i}=Y_{i}-T\left(Y_{i}\right), i=1,2,3$.

\footnotetext{
${ }^{7}$ Notice that, due to our assumption of a single (composite) private consumption good (and the absence of any intertemporal dimension in our analysis), claiming that people compare consumption is tantamount to claiming that they compare disposable (meaning after-tax) income. An alternative would have been to introduce two private consumption goods, let only the consumption of one of them affect the utility of other individuals, and jointly consider income and commodity taxes. However, on one hand the available literature seems to provide empirical support for the idea that income itself is "positional" in the sense that most individuals are also concerned with relative income and not just with relative consumption of particular goods (see e.g. Carlsson et al. (2007), Alpizar et al. (2005), Solnick and Hemenway (2005), Luttmer (2005) and Ferrer-i-Carbonel (2005) who also provides support for the view that comparisons are mostly "upwards"). On the other hand, as we will discuss in more details later on, the features of the income tax structure that we derive would also hold under the alternative modelling approach.
} 
As usual, due to the non-linearity of the tax schedule, the government must design the tax system so that each ability type (weakly) prefers the $(Y, C)$ bundle intended for it to those intended for the others (self-selection constraints). A household that misrepresents its type is called a mimicker.

Given that it is convenient to express the utility function in terms of observable variables, we introduce the following notation:

$$
\begin{aligned}
U\left(C_{i}, Y_{i} / w_{i}, G ; C_{i+1}\right) & =U^{i}\left(C_{i}, Y_{i}, G ; C_{i+1}\right) \\
\widetilde{U}\left(C_{i}, Y_{i} / w_{i}, G\right) & =\widetilde{U}^{i}\left(C_{i}, Y_{i}, G\right) .
\end{aligned}
$$

For given levels of consumption of the agents of type $j \neq i$, an agent of type $i$ chooses the pair $\left(Y_{i}, C_{i}\right)$ which maximizes his utility function subject to the budget constraint $C_{i}=Y_{i}-T\left(Y_{i}\right)$. Using subscripts to indicate partial derivatives, this yields the first order condition $-U_{Y_{i}}^{i} / U_{C_{i}}^{i}=1-\partial T\left(Y_{i}\right) / \partial Y_{i}$ for an agent who is not located at the top of the earning distribution, allowing to define implicitly the marginal income tax rate $T^{\prime}\left(Y_{i}\right)$ as:

$$
T^{\prime}\left(Y_{i}\right)=1+U_{Y_{i}}^{i} / U_{C_{i}}^{i}=1-M R S_{Y C}^{i},
$$

where $M R S_{Y C}^{i}$ denotes the marginal rate of substitution of a type $i$ agent between gross income and his own private consumption. ${ }^{8}$

Similarly, for the agents at the top of the earning distribution the implicit marginal tax rate can be defined as:

$$
T^{\prime}\left(Y_{i}\right)=1+\widetilde{U}_{Y_{i}}^{i} / \widetilde{U}_{C_{i}}^{i}=1-\widetilde{M R} S_{Y C}^{i} .
$$

We are now ready to present the government's problem. Following the relevant literature, we assume that the "agent monotonicity" property is satisfied and limit ourselves to the analysis of the so called "normal" case in which the government wants to redistribute from agents with higher ability to agents with lower ability and the only binding self-selection constraints are those running downwards and linking pair of adjacent types. ${ }^{9}$ Dropping

\footnotetext{
${ }^{8}$ It is well known that with a finite group of individuals an optimal tax function is generally nondifferentiable at the points at which the schedule is actually observed. However, since the utility functions are assumed to be differentiable, even if marginal income tax rates are not well defined at an optimal allocation it is possible to define implicit (shadow) marginal tax rates using the marginal rates of substitution.

${ }^{9}$ The "agent monotonicity" property states that, at any given point in the $(Y, C)$ space, the indifference curves are shallower the higher the wage rate of an agent: formally, $\partial\left(-U_{Y_{i}}^{i} / U_{C_{i}}^{i}\right) / \partial w<0$ and $\partial\left(-\widetilde{U}_{Y_{i}}^{i} / \widetilde{U}_{C_{i}}^{i}\right) / \partial w<0$. This assumption is in our model not more demanding than in a standard setting without Veblen effects. To see this, consider a generic bundle $\left(Y^{*}, C^{*}\right)$ in the $(Y, C)$-space and define with $M R S_{Y^{*} C^{*}}$ the marginal rate of substitution between gross income and own consumption at $\left(Y^{*}, C^{*}\right)$ for an agent
} 
arguments and writing $U^{i}$ and $\widetilde{U}^{i}$ for respectively $U^{i}\left(C_{i}, Y_{i}, G ; C_{i+1}\right)$ and $\widetilde{U}^{i}\left(C_{i}, Y_{i}, G\right)$, the government's problem can then be formally stated as:

$$
\max _{Y_{1}, C_{1}, Y_{2}, C_{2}, Y_{3}, C_{3}, G} \alpha_{3} \pi_{3} \widetilde{U}^{3}+\sum_{i=1}^{2} \alpha_{i} \pi_{i} U^{i}
$$

subject to:

$$
\begin{aligned}
& \widetilde{U}^{3} \geq U^{3,2}, \\
& U^{2} \geq U^{2,1} \\
& \sum_{i=1}^{3} \pi_{i}\left(Y_{i}-C_{i}\right) \geq p_{g} G,
\end{aligned}
$$

where $\alpha_{i}$ represent the positive welfare weights used by the government $\left(\sum_{i=1}^{3} \alpha_{i}=1\right)$, the Lagrange multipliers are within parentheses, and $U^{i, i-1}$ denotes the utility of an agent of type $i$ mimicking an agent of type $i-1$.

The following Proposition characterizes the optimal marginal tax rates faced by the different types of agents.

Proposition 1 The marginal income tax rates faced by the agents of type 3, 2 and 1 are respectively given by:

$$
\begin{gathered}
T^{\prime}\left(Y_{3}\right)=\underbrace{\frac{\widetilde{M R} S_{Y C}^{3}}{\gamma \pi_{3}}}_{>0}[\underbrace{-\left(\alpha_{2} \pi_{2}+\lambda^{2,1}\right) U_{C_{3}}^{2}}_{\Theta^{\prime}>0}+\underbrace{\lambda^{3,2} U_{C_{3}}^{3,2}}_{\Theta^{\prime \prime}<0}] ; \quad \underbrace{\frac{\lambda^{3,2} U_{C_{2}}^{3,2}}{\gamma \pi_{2}}}_{>0}(\underbrace{M R S_{Y C}^{2}-M R S_{Y C}^{3,2}}_{>0})+\underbrace{\frac{M R S_{Y C}^{2}}{\gamma \pi_{2}}}_{>0}(\underbrace{-\alpha_{1} \pi_{1} U_{C_{2}}^{1}}_{\Gamma^{\prime}>0}+\underbrace{\lambda^{2,1} U_{C_{2}}^{2,1}}_{\Gamma^{\prime \prime}<0}) ;
\end{gathered}
$$

with wage rate $w$. We can express $M R S_{Y^{*} C^{*}}$ as $\frac{-U_{L^{*}}\left(C^{*}, \frac{Y^{*}}{w}, G ; C^{+}\right)}{w U_{C^{*}}\left(C^{*}, \frac{Y^{*}}{w}, G ; C^{+}\right)}$, where $L^{*} \equiv \frac{Y^{*}}{w}$ and where we have denoted by $C^{+}$the consumption level of the next richest agent (if there is no such agent in the economy, then we are back to the standard case considered in the optimal taxation literature). We look for conditions under which $M R S_{Y^{*} C^{*}}$ is decreasing in the wage rate. Differentiating with respect to $w$ we obtain $\frac{\partial M R S_{Y^{*} C^{*}}}{\partial w}=$ $\frac{\frac{Y^{*}}{w} U_{L^{*} L^{*}} U_{C^{*}}+\left(U_{C^{*}}-\frac{Y^{*}}{w} U_{C^{*} L^{*}}\right) U_{L^{*}}}{\left(w U_{C^{*}}\right)^{2}}$, which is what one gets in the absence of Veblen effects. 


$$
T^{\prime}\left(Y_{1}\right)=\underbrace{\frac{\lambda^{2,1} U_{C_{1}}^{2,1}}{\gamma \pi_{1}}}_{>0}(\underbrace{M R S_{Y C}^{1}-M R S_{Y C}^{2,1}}_{>0}) .
$$

Proof. See the Appendix.

From Proposition 1 we get the result that, as compared to a model where an agent's utility does not depend on the consumption of others, our assumption of negative tuistic preferences modifies the structure of the optimal marginal tax rates for all agents, except for those at the bottom of the skill distribution.

According to eq. (5) the "no distortion at the top" result is violated: even for agents of type 3 the marginal tax rate is in general different from zero. However, the sign of the distortion is ambiguous. To get an insight on the effects driving eq. (5), consider what would happen if the government changed the bundle intended for type 3 agents from $\left(Y_{3}, C_{3}\right)$ to $\left(Y_{3}+d Y, C_{3}+\widetilde{M R} S_{Y C}^{3} d Y\right)$. Type 3 agents would in this case be induced to marginally increase pre-tax income along an indifference curve. Nonetheless, their incentives to mimic agents of type 2 would be weakened, given that $U_{C_{3}}^{3,2}<0$ and for a type 3 mimicker the private consumption gap between him and the next highest income agents has been widened. Thus, distorting upwards the labor supply of type 3 agents would have a beneficial effect in terms of mitigating the $\lambda^{3,2}$-constraint. This effect is captured in (5) by the term labelled $\Theta^{\prime \prime} .{ }^{10}$ However, the proposed change in the bundle offered to type 3 agents would also have two additional effects on agents of type 2 . More precisely, since $U_{C_{3}}^{2}<0$, the increased difference between the after-tax incomes of agents of type 3 and agents of type 2 makes the latter worse off. Because of that, social welfare is reduced for two reasons. First, directly, since the utility of type 2 agents is an argument in the social welfare function. Second, indirectly, since for type 2 agents mimicking becomes more attractive and therefore the $\lambda^{2,1}$-self-selection constraint tightens. This double effect is captured in (5) by the term labelled $\Theta^{\prime}$ which calls for distorting downwards the labor supply of agents of type 3 .

\footnotetext{
${ }^{10}$ Notice that the $\lambda^{3,2}$-constraint has been written under the assumption that when an agent of type 3 evaluates the utility that he would get by mimicking agents of type 2 , he takes into account the negative externality imposed on him by the consumption of the other, non-deviating, type 3 agents. This assumption is coherent with the idea that each agent behaves as a Nash competitor towards the other agents in the economy, taking their behavior as given. Otherwise, if all type 3 agents would be deviating at the same time, the $\lambda^{3,2}$-constraint in the government's problem should have been written as $\widetilde{U}^{3} \geq \widetilde{U}^{3,2}$ reflecting the fact that a type 3 mimicker would be preserving his rank as the richest agent in the economy and therefore would not be suffering from the negative externality imposed by the consumption of someone richer than him. In that case the term labelled $\Theta^{\prime \prime}$ would vanish from (5).
} 
Other things being equal, the more binding the $\lambda^{3,2}$-constraint and the higher the likelihood of getting a negative marginal tax rate for agents of type 3. Also, the chances of a negative marginal tax rate at the top are higher if agents' preferences are such that in (1) it is $\partial^{2} U / \partial C_{i+1} \partial L_{i}>0$, namely if a mimicker suffers more (than the person being mimicked) from increases in the wealth of the next highest income agents. ${ }^{11}$

As regards agents of type 2, the first term on the right side of eq. (6) is a standard self-selection term depending on the difference in the slopes of the indifference curves for a mimicker and for the agent being mimicked at the bundle intended for the latter. Since it is well known from previous analyses (see e.g. Stiglitz, 1982), we proceed further and consider the new terms in (6). Having already discussed (5), their interpretation is straightforward. Inducing agents of type 2 to marginally increase their pre-tax income would cause a detrimental effect on the welfare of type 1 agents and a beneficial effect on the self-selection constraint requiring type 2 agents to truthfully reveal their type. The former effect calls for an increase in $T^{\prime}\left(Y_{2}\right)$, the latter for a reduction. Other things being equal, the sign of $\Gamma^{\prime}+\Gamma^{\prime \prime}$ is more likely to be negative when the Lagrange multiplier $\lambda^{2,1}$ takes a high value and when agents' preferences are such that in (1) it is $\partial^{2} U / \partial C_{i+1} \partial L_{i}>0$.

As we already mentioned above, the expression for the marginal tax rate faced by agents of type 1 , given by eq. (7), does not differ from the expression which would have been obtained in a model where agents do not care about the consumption of others. ${ }^{12}$ For this reason, we will not provide further comments on this formula. It is sufficient to note that the marginal tax rate should be positive in order to distort the labor supply of type 1 agents downwards and in this way deter mimicking from agents of type 2 .

Summarizing, for all agents except those at the bottom of the skill distribution the presence of Veblen effects requires to include additional terms in the expressions for the optimal marginal tax rates. A reduction in the marginal tax rate imposed on a given type of agents may be desirable because, when the government is hampered by binding self-selection constraints running downwards, it represents an effective way to provide that type of agents

\footnotetext{
${ }^{11}$ The possibility of a negative marginal tax rate at the top cannot be ruled out because the argument put forward by Guesnerie and Seade (1982) on page 173 does no longer hold in this context. If, starting from a corner to which a negative marginal tax rate is associated, a new corner is created which lies south-west along the relevant indifference curve, the merely fact that a new bundle has become attainable implies that the mimicker's well-being is increased because the distance between the consumption level of a mimicker and of a higher income non-mimicker has been reduced.

${ }^{12}$ It should be clear by now that the reason for this result is that there is nobody behind them in the earning distribution, neither of a lower ability type nor a type 1 mimicker, to be affected by changes in their level of private consumption.
} 
with incentives to truthfully reveal their type. In general, for a given type of agents, the overall sign of the additional terms is more likely to be negative, thus working for a reduction in the marginal tax rate, under the following two circumstances:

i) the self-selection constraint requiring this type of agents to be deterred from mimicking is a severe constraint for the government in the sense that the value of the attached Lagrange multiplier is high;

ii) the marginal disutility of the negative externality is increasing in leisure so that in (1) the second order cross derivative $\partial^{2} U / \partial C_{i+1} \partial L_{i}$ takes a positive sign. This ensures that a mimicker is hurt more than the person he mimics from increases in the disposable income of those above him in earning distribution.

To further highlight that the possibility of negative marginal tax rates hinges crucially on the existence of binding self-selection constraints, it is instructive to consider the nature of first-best taxes. Our characterization of a second-best solution above allows us to do this most simply. At a first-best allocation, self-selection is not a constraint on the government's problem. Thus, setting $\lambda^{3,2}=\lambda^{2,1}=0$ in (5)-(7) yields respectively $T^{\prime}\left(Y_{3}\right)=-\frac{\widetilde{M R} S_{Y C}^{3}}{\gamma \pi_{3}} \alpha_{2} \pi_{2} U_{C_{3}}^{2}>0, T^{\prime}\left(Y_{2}\right)=-\frac{M R S_{Y C}^{2}}{\gamma \pi_{2}} \alpha_{1} \pi_{1} U_{C_{2}}^{1}>0$ and $T^{\prime}\left(Y_{1}\right)=0$. Therefore, a first-best optimum would entail all agents facing a positive marginal tax rate, except those at the bottom of the income distribution, for whom a "no distortion at the bottom" result would hold. The (personalized) positive marginal income tax rate induces agents to internalize the negative externality that their consumption creates at the margin. ${ }^{13}$ Since in our model the consumption of agents at the bottom of the income distribution does not impose any negative externality, those agents should remain undistorted at a first-best optimum.

Before considering the problem of the optimal level of public good provision, there are two issues that we would like to briefly discuss. The first regards our choice to focus on a separating equilibrium. As in all optimal taxation models with more than just two types, one must always keep in mind that there might be situations where an optimum is characterized by partial pooling (meaning that the government might offer the same $(Y, C)$ bundle to several types of individuals). ${ }^{14}$ Even if focusing on separating equilibria is a common practice in the optimal taxation literature, one might nonetheless wonder how the introduction of Veblen effects is going to influence the

\footnotetext{
${ }^{13}$ To be more precise, the positive marginal tax rate faced by agents of group $i$ serves the purpose of letting them internalize the negative externality that they impose, when marginally moving upwards along an indifference curve, on the next poorest agents (group $i-1)$. This can be seen more clearly by rewriting the expressions for the marginal tax rates on agents of type 3 and 2 as respectively $T^{\prime}\left(Y_{3}\right)=-\left(\alpha_{2} \pi_{2} / \gamma \pi_{3}\right) U_{C_{3}}^{2}\left(d C_{3} / d Y_{3}\right)_{d \widetilde{U}^{3}=0}>0$ and $T^{\prime}\left(Y_{2}\right)=-\left(\alpha_{1} \pi_{1} / \gamma \pi_{2}\right) U_{C_{2}}^{1}\left(d C_{2} / d Y_{2}\right)_{d U^{2}=0}>0$.

${ }^{14}$ Complete pooling can be ruled out since otherwise no redistribution would occur.
} 
likelihood of a partial pooling equilibrium. Even if a detailed analysis of this issue is beyond the scope of the present paper, intuition seems to suggest that partial pooling should not be an appealing option for the government. To see this, suppose for instance that agents of type 2 and 3 are pooled together and offered the same bundle. On the benefit side, we would have that only one group of agents, those of type 1, would be negatively affected by the wealth of richer agents. On the cost side, however, we should account both for the fact that the negative externality imposed on agents of type 1 is likely to be larger than in a separating equilibrium (since the gap between their consumption and the consumption of the next richest agent is likely to be larger in the case where agents of type 2 and 3 are bunched together) and for the fact that agents of type 2 would necessarily be net payers (since they are pooled with agents of type 3, they pay the same amount of tax as them, and this amount must be positive to allow financing a redistributive transfer to agents of type 1). The latter feature would only be irrelevant for the government under a Rawlsian objective function. Suppose instead that agents of type 2 are pooled with agents of type 1 . This case seems even less attractive than the previous one since both groups of agents would be facing the negative externality determined by the gap between $C_{3}$ and $C_{1}=C_{2}$. Offering agents of type 2 an intermediate bundle between that intended for agents of type 1 and that intended for agents of type 3 , it would be possible to reduce for both agents of type 1 and 2 the distance between their own consumption and the consumption of the next richest agent (which is what determines the negative externality).

The second issue that we want to briefly consider is how our results would have likely been affected if we had set up a model with many private goods where only the consumption of one of them negatively affects poorer neighbors. Imagine this to be the case and expand the government's set of instruments to allow for the possibility of differentiated commodity taxation. A commodity tax on the externality-generating good can then be regarded as the direct instrument to correct for the presence of Veblen effects. One might then wonder whether in such a setting a government would still want to use income taxation as an indirect instrument for externality-correcting purposes. The answer turns out to depends on whether the government has enough information to implement nonlinear commodity taxes or if informational constraints restrict it to the use of linear commodity taxes. ${ }^{15}$ The expressions for the optimal marginal income tax rates would not incorporate terms related to the presence of Veblen effects if the government could impose a nonlinear commodity tax on the consumption of the externalitygenerating good; otherwise, also the structure of the income tax would be

\footnotetext{
${ }^{15}$ Nonlinear commodity taxation requires the possibility to observe personal consumption levels of a given commodity, which is a very demanding assumption; linear commodity taxation only requires the observability of aggregate transactions.
} 
affected to cope with the presence of Veblen effects. The intuition for this result is similar to that provided in Micheletto (2008): ${ }^{16}$ even if there is only one externality-generating good, each agent's consumption of it generates a different externality. In other words, the Veblen effects of an increase in the consumption of the externality-generating good are different according to the identity of the agent that at the margin increases his consumption. A uniform (linear) commodity tax rate does therefore not suffice for externality-correcting purposes; also the structure of indirect instruments, as the income tax in our case, needs to be affected to reflect the presence of Veblen effects. Under this respect the nonlinear income tax is an especially valuable tool since it enables the government to let different agents face different marginal income tax rates. This is important because it allows the marginal tax rate faced by each specific type of agents to be more closely tailored to the Veblen effects descending from the consumption of the externality-generating commodity by that specific type of agents. ${ }^{17}$

Let's now consider the optimal level of public good provision. For this purpose let $M R S_{G C}^{i}$ denote the marginal rate of substitution between the public good and (his own) private consumption for a type $i$ individual who is not located at the top of the earning distribution: $M R S_{G C}^{i}=\frac{\partial U^{i} / \partial G}{\partial U^{i} / \partial C_{i}}$. Similarly, let the corresponding quantity for an agent at the top of the income distribution be denoted by $\widetilde{M R} S_{G C}^{i}=\frac{\partial \widetilde{U}^{i} / \partial G}{\partial \widetilde{U}^{i} / \partial C_{i}}$. Then, one can derive the following modified Samuelson rule:

Proposition 2 In the presence of optimal nonlinear income taxation, the efficient level of public good provision requires that:

$\pi_{3} \widetilde{M R} S_{G C}^{3}+\sum_{i=1}^{2} \pi_{i} M R S_{G C}^{i}=p_{g}+\underbrace{\sum_{i=2}^{3} \frac{\lambda^{i, i-1} \frac{\partial U^{i, i-1}}{\partial C_{i-1}}}{\gamma}\left(M R S_{G C}^{i, i-1}-M R S_{G C}^{i-1}\right)}_{\Pi}+\Omega$,

\footnotetext{
${ }^{16}$ See in particular Proposition 3 and the analysis contained in Section 4.

${ }^{17} \mathrm{~A}$ separate question is whether our expressions (5)-(7) would still be of some relevance for tax policy characterization purposes. The answer is yes. The main difference with respect to (5)-(7) would be that the Veblen-related terms in the expression for the marginal tax rate faced by agents of type $i$ would capture how their consumption of the externalitygenerating good (and not just their aggregate consumption) is affected if they were to marginally increase their level of pre-tax income.
} 
where $\Omega$ has been defined as:

$$
\begin{aligned}
\Omega= & \underbrace{\frac{\alpha_{1} \pi_{1} \frac{\partial U^{1}}{\partial C_{2}}}{\gamma} M R S_{G C}^{2}}_{\Delta^{\prime}<0}+\underbrace{\frac{\alpha_{2} \pi_{2} \frac{\partial U^{2}}{\partial C_{3}}}{\gamma} \widetilde{M R} S_{G C}^{3}}_{\Delta^{\prime \prime}<0} \\
& \underbrace{-\frac{\lambda^{2,1} \frac{\partial U^{2,1}}{\partial C_{2}}}{\gamma} M R S_{G C}^{2}}_{\Psi^{\prime}>0}+(\underbrace{-\frac{\lambda^{3,2} \frac{\partial U^{3,2}}{\partial C_{3}}}{\gamma}}_{\Psi^{\prime \prime}>0}+\underbrace{\frac{\lambda^{2,1} \frac{\partial U^{2}}{\partial C_{3}}}{\gamma}}_{\Psi^{\prime \prime \prime}<0}) \underbrace{\widetilde{M R} S_{G C}^{3}}_{>0}
\end{aligned}
$$

Proof. See the Appendix.

As compared to the second-best rule that one gets in the absence of Veblen effects (see for instance, for the case of a two-type economy, eq. (9) in Boadway and Keen, 1993) the new terms in eq. (8) are those collected in $\Omega$. For brevity, we will refer to a situation where $\Omega<(>) 0$ at the second-best optimum as involving overprovision (underprovision) of the public good relative to the corresponding modified Samuelson rule without Veblen effects.

Two of the terms defining $\Omega$ are welfare terms, the others are selfselection terms. The welfare terms appear in the first line of (9) and they both call for an upward distortion in the level of public good provision. Intuitively, since private consumption is the source of a negative externality, substituting public consumption for private consumption allows the government to increase social welfare. More precisely, suppose that the government is contemplating the possibility of marginally increasing the level of public good provision adjusting each individual's after-tax income by $d C_{i}=-M R S_{G C}^{i} d G<0$ for $i=1,2$ and by $d C_{i}=-\widetilde{M R} S_{G C}^{i} d G<0$ for $i=3$. Then, the left side of (8) measures the increase in tax revenue and the first term on the right side the increase in expenditure for the government following this reform. The well-being of the richest individual is clearly unaffected by the proposed reform $\left(d \widetilde{U}^{3}=0\right)$. However, given that $\partial U^{2} / \partial C_{3}<0$, the reduction in the after-tax income of agents of type 3 increases utility for all agents of type 2 and therefore raises social welfare by $-\alpha_{2} \pi_{2} \frac{\partial U^{2}}{\partial C_{3}} \widetilde{M R} S_{G C}^{3} d G$. Thus, the term labelled $\Delta^{\prime \prime}$ in (9) measures in terms of government's revenue the extent to which the net marginal cost of public good provision is lowered by this welfare-enhancing effect. Similarly, given that $\partial U^{1} / \partial C_{2}<0$, the reduction in the after-tax income of agents of type 2 increases utility for all agents of type 1 and therefore raises the social welfare by $-\alpha_{1} \pi_{1} \frac{\partial U^{1}}{\partial C_{2}} M R S_{G C}^{2}$. The term labelled $\Delta^{\prime}$ in (9) measures in terms of government's revenue the impact of this welfare-enhancing effect on the net marginal cost of public good provision.

Thus, the proposed reform would be welfare-enhancing for agents of type 1 and 2 and welfare-neutral for agents of type 3. This set of effects provides 
the underpinnings for the intuition that a model with spiteful agents offers a rationale for expanding the provision of public goods.

However, besides the welfare effects considered above, one also needs to take into account how the binding self-selection constraints of the government's problem are affected by the proposed reform.

A first set of effects is captured by the term labelled $\Pi$ on the right side of (8). These are self-selection terms which depend on how the personal value of the public good varies with an individual's market ability. Being familiar from previous analyses (see e.g. Boadway and Keen, 1993), we neglect them here and rather focus on the terms appearing in the second line of (9).

Consider for example the effect on the incentives for agents of type 3 to mimic agents of type 2 . The proposed reform leaves the utility of agents of type 3 unaffected. However, the substitution of public consumption for private consumption in the bundle intended for type 3 agents has an adverse self-selection effect (term labelled $\Psi^{\prime \prime}$ ) since it strengthens the incentives for type 3 agents to mimic type 2 agents. The reason is that for an agent of type 3 the cost of mimicking agents of type 2 is now reduced given the assumption that $\partial U^{3,2} / \partial C_{3}<0$ and given that $d C_{3}=-\widetilde{M R} S_{G C}^{i} d G<0$.

A similar adverse effect of a compensated marginal increase in $G$ is found if we consider the incentives for agents of type 2 to mimic agents of type 1 (see term labelled $\Psi^{\prime}$ ). In this case is the reduction in $C_{2}$ that, since $\partial U^{2,1} / \partial C_{2}<0$, lowers the cost for type 2 agents of mimicking type 1 agents. However, with respect to the incentives for agents of type 2 this is not the end of the story. An additional effect comes from the reduction of private consumption in the bundle intended for agents of type 3 . Since $\partial U^{2} / \partial C_{3}<0$, agents of type 2 are made better off and this by itself weakens their incentive to mimic, relaxing the $\lambda^{2,1}$-self-selection constraint (see term labelled $\left.\Psi^{\prime \prime \prime}\right) .{ }^{18}$

Summarizing, two of the three self-selection terms appearing in $\Omega$ take a positive sign; therefore, if the self-selection-based part of $\Omega$ takes a positive sign, it is possible that also the overall sign of $\Omega$ turns out being positive. In such a case we would get the counterintuitive result that the existence of Veblen effects distorts downwards the efficient level of public good provision. That this possibility hinges on the existence of self-selection constraints is immediate to ascertain by noticing that, if no self-selection constraint were binding at the solution to the government's problem (as in the case of a first-best solution), the sign of $\Omega$ would be unambiguously negative. ${ }^{19}$

\footnotetext{
${ }^{18}$ Notice that this welfare gain for the agents of type 2 was already responsible for the term $\Delta^{\prime \prime}$ in $(9)$. Here we need only to consider how it affects the $\lambda^{2,1}$-self-selection constraint.

${ }^{19}$ The right hand side of (8) would in this case be strictly smaller than $p_{g}$.
} 
Now let $M R S_{G Y}^{i}$ denote the marginal rate of substitution between the public good and pre-tax income for a type $i$ individual who is not located at the top of the earning distribution: $M R S_{G Y}^{i}=-\frac{\partial U^{i} / \partial G}{\partial U^{i} / \partial Y_{i}}$. Similarly, let the corresponding quantity for an agent at the top of the income distribution be denoted by $\widetilde{M R} S_{G Y}^{i}=-\frac{\partial \widetilde{U}^{i} / \partial G}{\partial \widetilde{U}^{i} / \partial Y_{i}}$. Then, using the expressions for the optimal marginal tax rates provided in Proposition 1, it is possible to rewrite the right side of (8) in the following way:

$$
\begin{aligned}
\pi_{3} \widetilde{M R} S_{G C}^{3}+\sum_{i=1}^{2} \pi_{i} M R S_{G C}^{i}= & p_{g} \\
& -\sum_{i=2}^{3} \frac{\lambda^{i, i-1} \partial U^{i, i-1} / \partial Y_{i-1}}{\gamma}\left(M R S_{G Y}^{i, i-1}-M R S_{G Y}^{i-1}\right) \\
& -\pi_{3} T^{\prime}\left(Y_{3}\right) \widetilde{M R} S_{G Y}^{3}-\sum_{i=1}^{2} \pi_{i} T^{\prime}\left(Y_{i}\right) M R S_{G Y}^{i} .
\end{aligned}
$$

The first thing to notice about (10) is that on its right side an individual's evaluation is assessed in terms of pre-tax income rather than private consumption. However, the virtue of eq. (10) is that it highlights the relation between the marginal tax rates and the variation in the net marginal cost of public good provision. In particular, it makes clear how a positive (negative) marginal tax rate contributes to lower (increase) the net marginal cost of public good provision. Thus, it also emphasizes that the Veblen effects, influencing the optimal marginal tax rates, also affect the second-best efficient level of public good provision.

Finally, substituting for $T^{\prime}\left(Y_{1}\right), T^{\prime}\left(Y_{2}\right)$ and $T^{\prime}\left(Y_{3}\right)$ in the last line of (10) the corresponding definitions of the implicit marginal tax rates ${ }^{20}$ and simplifying terms, one gets:

$\pi_{3} \widetilde{M R} S_{G Y_{3}}^{3}+\sum_{i=1}^{2} \pi_{i} M R S_{G Y_{i}}^{i}=p_{g}-\sum_{i=2}^{3} \frac{\lambda^{i, i-1} \partial U^{i, i-1} / \partial Y_{i-1}}{\gamma}\left(M R S_{G Y}^{i, i-1}-M R S_{G Y}^{i-1}\right)$

Notice that now the marginal rates of substitution appearing on the left side of (11) are between the public good and the pre-tax income. The interesting thing about (11) is then that, once all the individual's marginal evaluations of the public good are expressed in terms of pre-tax income, the rule governing the optimal level of public good provision boils down formally to the one that would be obtained in a model without Veblen effects. ${ }^{21}$ The

\footnotetext{
${ }^{20} T^{\prime}\left(Y_{1}\right)=1-M R S_{Y C}^{1}, T^{\prime}\left(Y_{2}\right)=1-M R S_{Y C}^{2}$ and $T^{\prime}\left(Y_{3}\right)=1-\widetilde{M R} S_{Y C}^{3}$.

${ }^{21}$ See for instance eq. (12) in Boadway and Keen (1993).
} 
reason for this result is that in our model the Veblen effects are related to a negative externality produced by private consumption. Thus, since no external effect is associated with pre-tax income (i.e. leisure time), no additional term due to the Veblen effects enters the formula for optimal public good provision when this is written in terms of the marginal rates of substitution between public good and pre-tax income.

\section{Laundering the individuals' preferences}

It is imperative that one should not dismiss negatively interdependent preferences because they seem "unethical". After all, if they dictate some of the economic decisions of the individuals, it is only natural that we include them in the realm of economic analysis. Nonetheless, preferences that involve envy are often treated as illegitimate, even without denying that agents have such preferences. The claim is simply that these preferences should carry no weight, from the normative point of view. The most striking formulation of this idea was provided by Robert Goodin (1986), with his image of "laundering preferences". The claim, roughly, is that a theory of justice will take preferences as "input", then apply some set of principles, or a social welfare function, in order to generate a normative ranking of possible states as "output". Such a theory may contain both an input and an output filter. The former will filter out illegitimate preferences, so that only certain preferences will count when it comes to determining social welfare. The latter will filter out recommendations that are trumped by other normative considerations (e.g., certain improvements in welfare might get ruled out, because achieving them would require unacceptable violations of individual rights).

In this Section we will explore how the formulas for the optimal marginal tax rates and the modified Samuelson rule for public good provision are going to be affected if the government launders the individuals' preferences in its objective function, depurating them from the envy component. In the context of our model the most natural way to operationalize this idea is to assume that the policy maker evaluates in its objective function the well-being of all types of agents according to the function $\widetilde{U}\left(C_{i}, L_{i}, G\right)$. This implies that, for all types of individuals except for those at the top of the income distribution, a wedge is inserted between the government's evaluation of the agents' well-being and the agent's evaluation of their own well-being.

If this is the case the government's problem can be formally written as:

$$
\max _{Y_{1}, C_{1}, Y_{2}, C_{2}, Y_{3}, C_{3}, G} \sum_{i=1}^{3} \alpha_{i} \pi_{i} \widetilde{U}^{i}
$$


subject to:

$$
\begin{array}{ll}
\widetilde{U}^{3} \geq U^{3,2}, & \left(\lambda^{3,2}\right) \\
U^{2} \geq U^{2,1}, & \left(\lambda^{2,1}\right) \\
\sum_{i=1}^{3} \pi_{i}\left(Y_{i}-C_{i}\right) \geq p_{g} G . & (\gamma)
\end{array}
$$

Notice that the only difference with the maximization problem presented in Section 2 relates to the objective function; in particular, the self-selection constraints do not change since the agents' incentives to mimic are always governed by their actual preferences. ${ }^{22}$

Denoting the right hand sides of (5), (6), (7) and (8) by, respectively, $T^{\prime}\left(Y_{3}\right)_{w e l f}, T^{\prime}\left(Y_{2}\right)_{\text {welf }}, T^{\prime}\left(Y_{1}\right)_{\text {welf }}$ and $N M C G_{\text {welf }}$, Proposition 3 characterizes the optimal fiscal policy for this modified government's problem. ${ }^{23}$

Proposition 3 Under the assumption that the policy maker launders the individuals' preferences in its objective function, the expressions for the optimal marginal tax rates become:

$$
\begin{gathered}
T^{\prime}\left(Y_{3}\right)=T^{\prime}\left(Y_{3}\right)_{\text {welf }}+\frac{\widetilde{M R} S_{Y C}^{3}}{\gamma \pi_{3}} \alpha_{2} \pi_{2} U_{C_{3}}^{2} ; \\
T^{\prime}\left(Y_{2}\right)=T^{\prime}\left(Y_{2}\right)_{\text {welf }}+\frac{M R S_{Y C}^{2}}{\gamma \pi_{2}} \alpha_{1} \pi_{1} U_{C_{2}}^{1}-\frac{\alpha_{2} \partial \widetilde{U}^{2} / \partial C_{2}}{\gamma}\left(M R S_{Y C}^{2}-\widetilde{M R} S_{Y C}^{2}\right) ; \\
T^{\prime}\left(Y_{1}\right)=T^{\prime}\left(Y_{1}\right)_{\text {welf }}-\frac{\alpha_{1} \partial \widetilde{U}^{1} / \partial C_{1}}{\gamma}\left(M R S_{Y C}^{1}-\widetilde{M R} S_{Y C}^{1}\right)
\end{gathered}
$$

Moreover, the efficient level of public good provision requires that:

$$
\begin{aligned}
\pi_{3} \widetilde{M R} S_{G C}^{3}+\sum_{i=1}^{2} \pi_{i} M R S_{G C}^{i}= & N M C G_{w e l f} \\
& -\left[\frac{\alpha_{1} \pi_{1} \frac{\partial U^{1}}{\partial C_{2}}}{\gamma} M R S_{G C}^{2}+\frac{\alpha_{2} \pi_{2} \frac{\partial U^{2}}{\partial C_{3}}}{\gamma} \widetilde{M R} S_{G C}^{3}\right] \\
& +\sum_{i=1}^{2} \frac{\alpha_{i} \pi_{i} \partial \widetilde{U}^{i} / \partial C_{i}}{\gamma}\left(M R S_{G C}^{i}-\widetilde{M R} S_{G C}^{i}\right) .
\end{aligned}
$$

\footnotetext{
${ }^{22}$ The approach followed in this Section is similar to the one developed in Blomquist and Micheletto (2006). However, public goods were not considered in that paper.

${ }^{23}$ The subscript welf is used to indicate that the expressions are derived from the maximization of a welfaristic objective function. The acronym $N M C G$ stands for net marginal cost of the public good $G$.
} 
Proof. See the Appendix.

Taking into account that $-\frac{\widetilde{M R} S_{Y C}^{3}}{\gamma \pi_{3}} \alpha_{2} \pi_{2} U_{C_{3}}^{2}$ appeared on the right side of (5), we can see that the only difference between (5) and (12) is that the latter does not incorporate terms that are not related to self-selection effects. The reason is apparent: since in the government's objective function the agents' preferences are depurated from the envy component, an increase in $C_{3}$ has per se no detrimental effect on the well-being of type 2 agents as assessed in the social welfare function. Nevertheless, type 2 agents experience a utilityreducing effect when $C_{3}$ increases and this effect is not completely neglected by the government. In particular, it matters to the extent that it affects the actual behavior of agents and, therefore, the self-selection constraints. Since in (5) the only term unrelated to self-selection effects pushes in the direction of increasing the marginal tax rate faced by type 3 agents, the structure of (12) seems to suggest that $T^{\prime}\left(Y_{3}\right)$ should be lower when agents' preferences are laundered in the government's objective function.

The second term on the right side of (13) is a corrective term that admits the same interpretation provided above for (12). It reflects the fact that, albeit type 1 agents perceive a utility-reducing effect from an increase in $C_{2}$, this effect does not appear in the government's objective function. With respect to (6) and (7) there is then an additional term in both (13) and (14). Since in both cases the structure of the new term is similar, here we limit our comments to (13). In this case the additional term is given by $-\frac{\alpha_{2} \partial \widetilde{U}^{2} / \partial C_{2}}{\gamma}\left(M R S_{Y C}^{2}-\widetilde{M R} S_{Y C}^{2}\right)$ and reflects how the trade-off between leisure and (own private) consumption is influenced by the assumption of negatively interdependent preferences. The quantity within brackets gives the difference between the minimum compensation required by the agents of type 2 to induce them to (work more and) marginally increase their gross income $\left(M R S_{Y C}^{2}\right)$ and the minimum compensation that would be required for the same purpose if the preferences of type 2 agents were represented by the (laundered) utility function $\widetilde{U}^{2}$ rather than $U^{2}$. Thus, given that $-\frac{\alpha_{2} \partial \widetilde{U}^{2} / \partial C_{2}}{\gamma}<0$, when this difference is negative (positive) the effect of the additional term is to push up (down) the marginal tax rate on agents of type 2. The intuition for the result is that, if the marginal valuation of leisure time (in terms of private consumption) for a type 2 person is lowered (increased) due to the Veblen effects, the government's disapproval of the agents' spiteful preferences makes it desirable to increase (reduce) the marginal income tax rate in order to distort downwards (upwards) their labor supply.

Since the common understanding of the phenomenon is that people tend to forgo too much leisure when they show a concern for relative levels of consumption (disposable income), we would expect that the relevant case is 
the one where the Veblen effects tend to lower an agent's marginal valuation of leisure. Formally, this means that

$$
\partial\left(-U_{Y_{i}}^{i} / U_{C_{i}}^{i}\right) / \partial C_{i+1}=\partial\left(-U_{L_{i}} / w U_{C_{i}}\right) / \partial C_{i+1}<0,
$$

namely that an agent's indifference curves in the $(Y, C)$-space become flatter with an increase in the consumption of the next highest income agents.

Thus, when (16) holds, the assumption that the government launders the individuals' preferences in its objective function implies that the last term in both (13) and (14) tends to raise the marginal tax rate.

Given that $\partial^{2} U / \partial C_{i} \partial C_{i+1}>0$ seems a quite plausible assumption, a sufficient condition for (16) is that $\partial^{2} U / \partial L_{i} \partial C_{i+1} \geq 0$. Interestingly, $\partial^{2} U / \partial L_{i} \partial C_{i+1}>0$ is a condition which we had already singled out in Section 2, where it was assumed that the government did respect the individuals' preferences in its social welfare function. In that case it represented one of the conditions which increased the likelihood that, for a given type of agents, the overall sign of the additional terms due to the presence of Veblen effects were negative, thus contributing to a reduction in the marginal tax rate. Thus, the same condition which, due to the effects on the self-selection constraints, might call for a reduction in marginal tax rates in a welfaristic setting, might also favour, for difference-in-preferences considerations, an increase in marginal tax rates in a non-welfaristic setting where the government launders the agents' preferences in its objective function.

Turning now our attention to eq. (15) which implicitly defines the optimal level of public good provision, we can see that, as compared to (8), there are two sets of additional terms. The terms within square brackets reflect the fact that, in a setting where Veblen effects are neglected in the government's objective function, some of the benefits descending from substituting public good for private consumption are lost. The reason is that in such a setting a reduction in the private consumption of agents of type $i(i=2,3)$ does not produce any beneficial effect on the well-being of agents of type $i-1$ as this is assessed in the government's objective function. Thus, the terms within square brackets in (15) tend to favour a reduction in the efficient level of $G$. The second set of new terms in (15) (those appearing in the last line) depend on the difference between the marginal willingness to pay (in terms of private consumption) for the public good of an actual type $i(i=1,2)$ agent and of a (non-spiteful) agent of type $i$ who had preferences represented by the utility function $\widetilde{U}$. The intuition is once again straightforward. Since the government is evaluating the agents' well-being according to the utility function $\widetilde{U}$ which is different from the one maximized by (some of) them, a substitution of public good for private consumption which is welfare-neutral for an actual agent might well be deemed non-neutral from the government's perspective. 
In particular, it will be considered welfare-reducing or welfare-enhancing depending respectively on whether the marginal rate of substitution between public good and private consumption for the actual agent exceeds or falls short of the corresponding marginal rate of substitution for an agent with preferences represented by $\widetilde{U}$. Thus, if the marginal valuation of the public good (in terms of private consumption) is lowered (increased) due to the Veblen effects, namely if $\partial\left(U_{G}^{i} / U_{C_{i}}^{i}\right) / \partial C_{i+1}<(>) 0$, expanding the level of public good provision entails an additional gain (loss) for a government which shows disapproval of the agents' spiteful preferences. ${ }^{24}$

\section{A numerical example}

In this Section we provide a simple numerical example to support the claim that, as predicted by our theoretical analysis, the introduction of Veblen effects might in some cases lead to a reduction in optimal marginal tax rates. For this purpose, let $U\left(C_{i}, L_{i}, G ; C_{i+1}\right)$ and $\widetilde{U}\left(C_{i}, L_{i}, G\right)$ be given by

$$
\begin{aligned}
U\left(C_{i}, L_{i}, G ; C_{i+1}\right) & =\ln C_{i}+G^{1 / 4}-\theta L^{2}-\beta\left[C_{i+1}-C_{i}\right]^{2}+\delta L\left[C_{i+1}-C_{i}\right] \\
\widetilde{U}\left(C_{i}, L_{i}, G\right) & =\ln C_{i}+G^{1 / 4}-\theta L^{2} .
\end{aligned}
$$

Take $w_{1}=1, w_{2}=2, w_{3}=3$ and $p_{g}=0.5$. The proportion of agents are $\pi_{1}=0.3, \pi_{2}=0.3$ and $\pi_{3}=0.4$. Each welfare weight $\alpha_{i}$ is set equal to $1 / 3$. Finally, the remaining parametric assumptions are $\theta=2, \beta=1.5$ and $\delta=2.1 .^{25}$

Table 1 represents the calculated optimal marginal tax rates, equilibrium allocations and levels of public good provision. ${ }^{26}$

$\begin{array}{llll}\text { Table 1 }(\delta=2.1) & \text { Veblen effects } & \text { No Veblen effects } & \text { Laundering } \\ T^{\prime}\left(Y_{1}\right) & 45.86 \% & 39.48 \% & 71.63 \% \\ T^{\prime}\left(Y_{2}\right) & 39.75 \% & 43.27 \% & 87.68 \% \\ T^{\prime}\left(Y_{3}\right) & -10.74 \% & 0 \% & -23.91 \% \\ \left(Y_{1}, B_{1}\right) & (0.3967,0.6049) & (0.2861,0.5288) & (0.2483,0.5754) \\ \left(Y_{2}, B_{2}\right) & (1.2564,0.9117) & (0.8795,0.7474) & (0.8847,0.7950) \\ \left(Y_{3}, B_{3}\right) & (1.7819,1.3983) & (1.7751,1.2676) & (2.0062,1.3896) \\ G & 0.39 & 0.34 & 0.35\end{array}$

\footnotetext{
${ }^{24}$ With $\partial^{2} U / \partial C_{i} \partial C_{i+1}>0$, a sufficient condition for $\partial\left(U_{G}^{i} / U_{C_{i}}^{i}\right) / \partial C_{i+1}<0$ is that $\partial^{2} U / \partial G \partial C_{i+1} \leq 0$.

${ }^{25}$ Concavity of the utility functions requires $\theta>0, \beta>0$ and $4 \theta \beta-\delta^{2}>0$. The last inequality implies $-2[\theta \beta]^{1 / 2}<\delta<2[\theta \beta]^{1 / 2}$.

${ }^{26}$ In performing the numerical simulations we have explicitly considered all the possible self-selection constraints (which in our case are 6 since we have a three-type model). The obtained results confirms that the solution to the government's problem entails a separating equilibrium where the only binding self-selection constraints are those running downwards and linking pair of adjacent types.
} 
The first column reports the values for the case where Veblen effects are present and the government respects the individuals' preferences in its objective function. The second column reports the values for the case where Veblen effects are absent. Finally, the last column reports the values for the case where Veblen effects are present but the government launders the individuals' preferences in its objective function.

As we can see, $T^{\prime}\left(Y_{3}\right)$ is negative in the presence of Veblen effects whereas a standard "no distortion at the top" result is obtained in the absence of Veblen effects. This clearly illustrates that the introduction of Veblen effects might indeed lead some agents to face lower marginal tax rates. ${ }^{27}$ As we have observed in the discussion of Proposition 1, this possibility is more likely to occur when $\partial^{2} U / \partial C_{i+1} \partial L_{i}>0$, implying that a mimicker is hurt more than the mimicked from increases in the consumption of those above him in the earning distribution. For our specification of $U(\cdot)$ this requires a positive value for the parameter $\delta{ }^{28}$ Table 2 below, where we report results for the cases where $\delta=1.3$ and $\delta=-1$, shows that $\partial^{2} U / \partial C_{i+1} \partial L_{i}>0$ is not a sufficient condition to get a negative value for $T^{\prime}\left(Y_{3}\right)$ and that, as $\delta$ is decreased, all the marginal tax rates become larger. Comparing the value of $G$ in the last column of table 2 with the one that was obtained without Veblen effects (see table 1), we can also see that Veblen effects may entail a reduction in the efficient level of public good provision.

$\begin{array}{lll}\text { Table } 2 & \text { Veblen effects }(\delta=1.3) & \text { Veblen effects }(\delta=-1) \\ T^{\prime}\left(Y_{1}\right) & 49.45 \% & 53.20 \% \\ T^{\prime}\left(Y_{2}\right) & 49.61 \% & 60.49 \% \\ T^{\prime}\left(Y_{3}\right) & 10.05 \% & 34.23 \% \\ \left(Y_{1}, B_{1}\right) & (0.3502,0.5765) & (0.2718,0.5383) \\ \left(Y_{2}, B_{2}\right) & (1.0366,0.8442) & (0.8240,0.7624) \\ \left(Y_{3}, B_{3}\right) & (1.6802,1.2046) & (1.5235,0.9713) \\ G & 0.36 & 0.32\end{array}$

\section{Concluding remarks}

We have studied how the presence of Veblen effects affect the shape of the optimal nonlinear income tax and the efficient level of public good provision in an asymmetric information setting where individuals' market abilities are private information and the government aims at redistributing income. The

\footnotetext{
${ }^{27}$ Notice also that, as suggested by our discussion in Section 3, the marginal tax rate faced by agents of type 3 is even lower in the "laundering" case.

${ }^{28}$ With $\theta=2$ and $\beta=1.5$, the assumption that $\delta=2.1$ is coherent with the requirement, needed to ensure concavity of $U(\cdot)$, that $-2[\theta \beta]^{1 / 2}<\delta<2[\theta \beta]^{1 / 2}$. One can also easily check that, with this parameter specification, both $\partial U / \partial L_{i}<0$ and $\partial U / \partial C_{i+1}<0$ are verified at the equilibrium allocations that solve the government's problem.
} 
focus has been on the case where agents get disutility from the consumption (disposable income) of the next highest income individuals.

We have shown that for all agents except those at the bottom of the skill distribution the presence of Veblen effects requires to include additional terms in the expressions for the optimal marginal tax rates Contrary to previous analyses we have emphasized that, due to the effects on the self-selection constraints to the government's problem, the overall sign of the additional terms might be negative, contributing to a reduction in the marginal tax rates. We have also highlighted that the same effects on the self-selection constraints are responsible for the fact that, when deriving a modified Samuelson rule for the efficient level of public expenditure, the Veblen-based part of the formula might lead to an increase in the net marginal cost of public good provision.

In the last part of the paper we have considered how the results are affected assuming that the government shows disapproval of the agents' spiteful preferences and launders them in its objective function. We have shown that in general the expressions for the marginal tax rates are amended by the appearance of two new terms. The first term tends to lower the marginal tax rates. The second term has instead the opposite effect under the assumption that an agent's marginal valuation of leisure time is lowered due to the Veblen effects. A special attention has been devoted to the condition requiring that for a given agent the marginal disutility of labor is reduced by an increase in the consumption of the next highest income individuals. We have underlined how this condition which, due to the effects on the self-selection constraints, might be responsible for a reduction in the marginal tax rates in a welfaristic setting, might also warrant, for difference-in-preferences considerations, an increase in marginal tax rates in a setting where the government launders the agents' preferences in its objective function. Finally, we have derived a modified Samuelson rule for the case where the government's and agents' preferences differ and we have shown that this gives rise to two sets of additional terms. A first group of terms provide the government with incentives to underprovide the public good whereas, under the assumption that an agent's marginal valuation of the public good is lowered due to the Veblen effects, a second group of terms tend to lower the net marginal cost of public good provision.

\section{Appendix}

\subsection{Proof of Proposition 1}

The first order conditions of the government's problem with respect to $Y_{1}$, $C_{1}, Y_{2}, C_{2}, Y_{3}$ and $C_{3}$ are respectively given by:

$Y_{1}: \quad \alpha_{1} \pi_{1} \partial U^{1} / \partial Y_{1}=\lambda^{2,1} \partial U^{2,1} / \partial Y_{1}-\gamma \pi_{1}$

$C_{1}: \quad \alpha_{1} \pi_{1} \partial U^{1} / \partial C_{1}=\lambda^{2,1} \partial U^{2,1} / \partial C_{1}+\gamma \pi_{1}$ 
$Y_{2}: \quad\left(\alpha_{2} \pi_{2}+\lambda^{2,1}\right) \partial U^{2} / \partial Y_{2}=\lambda^{3,2} \partial U^{3,2} / \partial Y_{2}-\gamma \pi_{2}$

$C_{2}: \quad\left(\alpha_{2} \pi_{2}+\lambda^{2,1}\right) \partial U^{2} / \partial C_{2}=\gamma \pi_{2}-\alpha_{1} \pi_{1} \partial U^{1} / \partial C_{2}+\lambda^{3,2} \partial U^{3,2} / \partial C_{2}+$ $\lambda^{2,1} \partial U^{2,1} / \partial C_{2}$

$Y_{3}: \quad\left(\alpha_{3} \pi_{3}+\lambda^{3,2}\right) \partial \widetilde{U}^{3} / \partial Y_{3}=-\gamma \pi_{3}$

$C_{3}: \quad\left(\alpha_{3} \pi_{3}+\lambda^{3,2}\right) \partial \widetilde{U}^{3} / \partial C_{3}=\gamma \pi_{3}-\alpha_{2} \pi_{2} \partial U^{2} / \partial C_{3}+\lambda^{3,2} \partial U^{3,2} / \partial C_{3}-$ $\lambda^{2,1} \partial U^{2} / \partial C_{3}$

Dividing (A5) by (A6) and multiplying both sides by the right side of (A6) gives:

$\frac{\partial \widetilde{U}^{3} / \partial Y_{3}}{\partial \widetilde{U}^{3} / \partial C_{3}}\left[\gamma \pi_{3}-\alpha_{2} \pi_{2} \partial U^{2} / \partial C_{3}+\lambda^{3,2} \partial U^{3,2} / \partial C_{3}-\lambda^{2,1} \partial U^{2} / \partial C_{3}\right]=-\gamma \pi_{3}$.

Using (4) to rearrange terms in the equation above provides (5).

Using (3) and applying a similar procedure first on the f.o.c. (A3) and (A4) and then on (A1) and (A2) gives (6) and (7).

\subsection{Proof of Proposition 2}

The first order condition of the government's problem with respect to $G$ is:

$G: \quad \alpha_{1} \pi_{1} \partial U^{1} / \partial G+\left(\alpha_{2} \pi_{2}+\lambda^{2,1}\right) \partial U^{2} / \partial G+\left(\alpha_{3} \pi_{3}+\lambda^{3,2}\right) \partial \widetilde{U}^{3} / \partial G-$ $\lambda^{3,2} \partial U^{3,2} / \partial G-\lambda^{2,1} \partial U^{2,1} / \partial G=\gamma p_{g}$

Adding and subtracting to (A7) $\lambda^{3,2} \partial U^{3,2} / \partial C_{2} \frac{\partial U^{2} / \partial G}{\partial U^{2} / \partial C_{2}}+\lambda^{2,1} \partial U^{2,1} / \partial C_{1} \frac{\partial U^{1} / \partial G}{\partial U^{1} / \partial C_{1}}$ and rearranging terms allows to rewrite the f.o.c. for $G$ as:

$$
\begin{aligned}
& \left(\alpha_{3} \pi_{3}+\lambda^{3,2}\right) \partial \widetilde{U}^{3} / \partial C_{3} \frac{\partial \widetilde{U}^{3} / \partial G}{\partial \widetilde{U}^{3} / \partial C_{3}}+\left(\alpha_{1} \pi_{1} \partial U^{1} / \partial C_{1}-\lambda^{2,1} \partial U^{2,1} / \partial C_{1}\right) \frac{\partial U^{1} / \partial G}{\partial U^{1} / \partial C_{1}} \\
& +\left(\alpha_{2} \pi_{2} \partial U^{2} / \partial C_{2}-\lambda^{3,2} \partial U^{3,2} / \partial C_{2}+\lambda^{2,1} \partial U^{2} / \partial C_{2}\right) \frac{\partial U^{2} / \partial G}{\partial U^{2} / \partial C_{2}} \\
& +\lambda^{2,1} \partial U^{2,1} / \partial C_{1}\left(\frac{\partial U^{1} / \partial G}{\partial U^{1} / \partial C_{1}}-\frac{\partial U^{2,1} / \partial G}{\partial U^{2,1} / \partial C_{1}}\right)+\lambda^{3,2} \partial U^{3,2} / \partial C_{2}\left(\frac{\partial U^{2} / \partial G}{\partial U^{2} / \partial C_{2}}-\frac{\partial U^{3,2} / \partial G}{\partial U^{3,2} / \partial C_{2}}\right) \\
= & \gamma p_{g} .
\end{aligned}
$$

Use (A2), (A4) and (A6) to get respectively expressions for $\alpha_{1} \pi_{1} \partial U^{1} / \partial C_{1}-$ $\lambda^{2,1} \partial U^{2,1} / \partial C_{1},\left(\alpha_{2} \pi_{2}+\lambda^{2,1}\right) \partial U^{2} / \partial C_{2}-\lambda^{3,2} \partial U^{3,2} / \partial C_{2}$ and $\left(\alpha_{3} \pi_{3}+\lambda^{3,2}\right) \partial \widetilde{U}^{3} / \partial C_{3}$.

Substituting these expressions in (A8) and rearranging terms gives the result stated in Proposition 2.

\subsection{Proof of Proposition 3}

The f.o.c. for $Y_{3}$ is still given by (A5). The f.o.c. for $C_{3}$ differs from (A6) because the term $-\alpha_{2} \pi_{2} \partial U^{2} / \partial C_{3}$ is now absent. Thus, the only difference between (5) and the optimal marginal tax rate faced by agents of type 3 in the laundering case is the absence in the latter of any term depending on $\alpha_{2} \pi_{2} \partial U^{2} / \partial C_{3}$. The other first order conditions become:

$Y_{1}: \quad \alpha_{1} \pi_{1} \partial U^{1} / \partial Y_{1}=\lambda^{2,1} \partial U^{2,1} / \partial Y_{1}-\gamma \pi_{1}+\xi_{Y}^{1}$ 
$C_{1}: \quad \alpha_{1} \pi_{1} \partial U^{1} / \partial C_{1}=\lambda^{2,1} \partial U^{2,1} / \partial C_{1}+\gamma \pi_{1}+\xi_{C}^{1}$

$Y_{2}:\left(\alpha_{2} \pi_{2}+\lambda^{2,1}\right) \partial U^{2} / \partial Y_{2}=\lambda^{3,2} \partial U^{3,2} / \partial Y_{2}-\gamma \pi_{2}+\xi_{Y}^{2}$ $\xi_{C}^{2}$

$C_{2}: \quad\left(\alpha_{2} \pi_{2}+\lambda^{2,1}\right) \partial U^{2} / \partial C_{2}=\lambda^{3,2} \partial U^{3,2} / \partial C_{2}+\gamma \pi_{2}+\lambda^{2,1} \partial U^{2,1} / \partial C_{2}+$

$\partial U^{1} / \partial G+\left(\alpha_{2} \pi_{2}+\lambda^{2,1}\right) \partial U^{2} / \partial G+\left(\alpha_{3} \pi_{3}+\lambda^{3,2}\right) \partial U^{3} / \partial G-$ $\lambda^{3,2} \partial U^{3,2} / \partial G-\lambda^{2,1} \partial U^{2,1} / \partial G=\gamma p_{g}+\xi_{G}$,

where, for $i=1,2, \xi_{Y}^{i}=\alpha_{i} \pi_{i} \partial U^{i} / \partial Y_{i}-\alpha_{i} \pi_{i} \partial \widetilde{U}^{i} / \partial Y_{i}, \xi_{C}^{i}=\alpha_{i} \pi_{i} \partial U^{i} / \partial C_{i}-$ $\alpha_{i} \pi_{i} \partial \widetilde{U}^{i} / \partial C_{i}$, and finally $\xi_{G}=\sum_{i=1}^{2}\left(\alpha_{i} \pi_{i} \partial U^{i} / \partial G-\alpha_{i} \pi_{i} \partial \widetilde{U}^{i} / \partial G\right)$.

Dividing (A11) by (A12) and multiplying both sides by the right side of (A12) gives:

$$
\frac{\partial U^{2} / \partial Y_{2}}{\partial U^{2} / \partial C_{2}}\left[\lambda^{3,2} \partial U^{3,2} / \partial C_{2}+\gamma \pi_{2}+\lambda^{2,1} \partial U^{2,1} / \partial C_{2}+\xi_{C}^{2}\right]=\lambda^{3,2} \partial U^{3,2} / \partial Y_{2}-
$$
$\gamma \pi_{2}+\xi_{Y}^{2}$.

Eq. (13) is obtained using (3) to rearrange terms in the equation above and noticing that $\xi_{Y}^{2}-\xi_{C}^{2} \frac{\partial U^{2} / \partial Y_{2}}{\partial U^{2} / \partial C_{2}}=\alpha_{2} \pi_{2}\left[\frac{\partial U^{2} / \partial Y_{2}}{\partial U^{2} / \partial C_{2}}-\frac{\partial \widetilde{U}^{2} / \partial Y_{2}}{\partial \widetilde{U}^{2} / \partial C_{2}}\right] \partial \widetilde{U}^{2} / \partial C_{2}$.

Applying a similar procedure on the f.o.c. (A9) and (A10) and noticing that $\xi_{Y}^{1}-\xi_{C}^{1} \frac{\partial U^{1} / \partial Y_{1}}{\partial U^{1} / \partial C_{1}}=\alpha_{1} \pi_{1}\left[\frac{\partial U^{1} / \partial Y_{1}}{\partial U^{1} / \partial C_{1}}-\frac{\partial \widetilde{U}^{1} / \partial Y_{1}}{\partial \widetilde{U}^{1} / \partial C_{1}}\right] \partial \widetilde{U}^{1} / \partial C_{1}$ gives (14).

Adding and subtracting to (A13) $\lambda^{3,2} \partial U^{3,2} / \partial C_{2} \frac{\partial U^{2} / \partial G}{\partial U^{2} / \partial C_{2}}+\lambda^{2,1} \partial U^{2,1} / \partial C_{1} \frac{\partial U^{1} / \partial G}{\partial U^{1} / \partial C_{1}}$ and rearranging terms allows to rewrite the f.o.c. for $G$ as:

$$
\begin{aligned}
& \left(\alpha_{3} \pi_{3}+\lambda^{3,2}\right) \partial \widetilde{U}^{3} / \partial C_{3} \frac{\partial \widetilde{U}^{3} / \partial G}{\partial \widetilde{U}^{3} / \partial C_{3}}+\left(\alpha_{1} \pi_{1} \partial U^{1} / \partial C_{1}-\lambda^{2,1} \partial U^{2,1} / \partial C_{1}\right) \frac{\partial U^{1} / \partial G}{\partial U^{1} / \partial C_{1}} \\
+ & \left(\alpha_{2} \pi_{2} \partial U^{2} / \partial C_{2}-\lambda^{3,2} \partial U^{3,2} / \partial C_{2}+\lambda^{2,1} \partial U^{2} / \partial C_{2}\right) \frac{\partial U^{2} / \partial G}{\partial U^{2} / \partial C_{2}} \\
& +\lambda^{2,1} \partial U^{2,1} / \partial C_{1}\left(\frac{\partial U^{1} / \partial G}{\partial U^{1} / \partial C_{1}}-\frac{\partial U^{2,1} / \partial G}{\partial U^{2,1} / \partial C_{1}}\right)+\lambda^{3,2} \partial U^{3,2} / \partial C_{2}\left(\frac{\partial U^{2} / \partial G}{\partial U^{2} / \partial C_{2}}-\frac{\partial U^{3,2} / \partial G}{\partial U^{3,2} / \partial C_{2}}\right) \\
= & \gamma p_{g}+\alpha_{1} \pi_{1} \partial U^{1} / \partial G-\alpha_{1} \pi_{1} \partial \widetilde{U}^{1} / \partial G+\alpha_{2} \pi_{2} \partial U^{2} / \partial G-\alpha_{2} \pi_{2} \partial \widetilde{U}^{2} / \partial G . \quad \text { (A14) }
\end{aligned}
$$

Use (A10), (A12) and (A6) to get respectively expressions for $\alpha_{1} \pi_{1} \partial U^{1} / \partial C_{1}-$ $\lambda^{2,1} \partial U^{2,1} / \partial C_{1},\left(\alpha_{2} \pi_{2}+\lambda^{2,1}\right) \partial U^{2} / \partial C_{2}-\lambda^{3,2} \partial U^{3,2} / \partial C_{2}$ and $\left(\alpha_{3} \pi_{3}+\lambda^{3,2}\right) \partial \widetilde{U}^{3} / \partial C_{3}$.

Substituting these expressions in (A14) and using the definitions of $\xi_{C}^{i}$ $(i=1,2)$ gives: 


$$
\begin{aligned}
& {\left[\gamma \pi_{3}+\lambda^{3,2} \partial U^{3,2} / \partial C_{3}-\lambda^{2,1} \partial U^{2} / \partial C_{3}\right] \frac{\partial \widetilde{U}^{3} / \partial G}{\partial \widetilde{U}^{3} / \partial C_{3}} } \\
& +\left(\gamma \pi_{1}+\alpha_{1} \pi_{1} \partial U^{1} / \partial C_{1}-\alpha_{1} \pi_{1} \partial \widetilde{U}^{1} / \partial C_{1}\right) \frac{\partial U^{1} / \partial G}{\partial U^{1} / \partial C_{1}} \\
& +\left[\gamma \pi_{2}+\lambda^{2,1} \partial U^{2,1} / \partial C_{2}+\alpha_{2} \pi_{2} \partial U^{2} / \partial C_{2}-\alpha_{2} \pi_{2} \partial \widetilde{U}^{2} / \partial C_{2}\right] \frac{\partial U^{2} / \partial G}{\partial U^{2} / \partial C_{2}} \\
& +\lambda^{2,1} \partial U^{2,1} / \partial C_{1}\left(\frac{\partial U^{1} / \partial G}{\partial U^{1} / \partial C_{1}}-\frac{\partial U^{2,1} / \partial G}{\partial U^{2,1} / \partial C_{1}}\right)+\lambda^{3,2} \partial U^{3,2} / \partial C_{2}\left(\frac{\partial U^{2} / \partial G}{\partial U^{2} / \partial C_{2}}-\frac{\partial U^{3,2} / \partial G}{\partial U^{3,2} / \partial C_{2}}\right) \\
= & \gamma p_{g}+\alpha_{1} \pi_{1} \partial U^{1} / \partial G-\alpha_{1} \pi_{1} \partial \widetilde{U}^{1} / \partial G+\alpha_{2} \pi_{2} \partial U^{2} / \partial G-\alpha_{2} \pi_{2} \partial \widetilde{U}^{2} / \partial G . \quad(\mathrm{A} 15)
\end{aligned}
$$

Simplifying and rearranging terms in (A15) gives (15).

\section{References}

[1] Alpizar, A., Carlsson, F. and O. Johansson-Stenman (2005), "How much do we care about absolute versus relative income and consumption?", Journal of Economic Behavior \& Organization 56, 405-421.

[2] Balestrino, A. (2006), "Tax avoidance, endogenous social norms, and the comparison income effect", CESifo working paper No. 1758.

[3] Blomquist, S. and L. Micheletto (2006), "Optimal redistributive taxation when government's and agents' preferences differ", Journal of Public Economics 90, 1215-1233.

[4] Boadway, R. and M. Keen (1993), "Public goods, self-selection and optimal income taxation", International Economic Review 34, 463-478.

[5] Boskin, M. J. and E. Sheshinski (1978), "Optimal redistributive taxation when individual welfare depends upon relative income", Quarterly Journal of Economics 92, 589-601.

[6] Bowles, S. and Y. Park (2005), "Emulation, inequality, and work hours: was Thorsten Veblen right?", The Economic Journal 115, 397-412.

[7] Carlsson, F., Johansson-Stenman, O. and P. Martinsson (2007), "Do you enjoy having more than others? Survey evidence of positional goods", Economica 74, 586-598.

[8] Corneo, G. (2002), "The efficient side of progressive income taxation", European Economic Review 46, 1359-1368. 
[9] Duesenberry, J. A. (1949), Income, saving and the theory of consumer behaviour, Harvard University Press.

[10] Easterlin, R. (1974), "Does economic growth improve the human lot? Some empirical evidence", in Nations and households in economic growth: essays in honor of Moses Abramovitz, New York: Academic Press.

[11] Ferrer-i-Carbonell, A. (2005), "Income and well-being: an empirical analysis of the comparison income effect", Journal of Public Economics 89, 997-1019.

[12] Frank, R. (1985), Choosing the right pond: human behavior and the quest for status, Oxford University Press.

[13] Galbraith, J. K. (1958), The affluent society, Boston: Houghton Mifflin Company.

[14] Gauthier, D. (1986), Morals by agreement, Oxford University Press.

[15] Goodin, R. (1986), "Laundering preferences", in J. Elster and A. Hylland, ed., Foundations of Social Choice Theory, Cambridge University Press.

[16] Guesnerie, R. and J. Seade (1982), "Nonlinear pricing in a finite economy", Journal of Public Economics 17, 157-179.

[17] Hirsch, F. (1976), Social limits to growth, Harvard University Press.

[18] Ireland, N. J. (2001), "Optimal income tax in the presence of status effects", Journal of Public Economics 81, 193-212.

[19] Layard, R. (1980), "Human satisfactions and public policy", The Economic Journal 90, 737-750.

[20] Leibenstein, H. (1950), "Bandwagon, snob, and Veblen effects in the theory of consumers' demand", Quarterly Journal of Economics 64, 183-207.

[21] Luttmer, E. F. P. (2005), "Neighbors as negatives: relative earnings and well-being", Quarterly Journal of Economics 120, 963-1002.

[22] Micheletto, L. (2008), "Redistribution and optimal mixed taxation in the presence of consumption externalities", Journal of Public Economics 92, 2262-2274.

[23] Mirrlees, J. (1971), "An exploration in the theory of optimum income taxation", Review of Economic Studies 38, 175-208. 
[24] Ng, Y. Q. (1987), "Relative-income effects and the appropriate level of public expenditure", Oxford Economic Papers 39, 293-300.

[25] Ok E. A. and L. Kockesen (2000), "Negatively interdependent preferences", Social Choice and Welfare 17, 533-558.

[26] Oswald A. J. (1983), "Altruism, jealousy and the theory of optimal non-linear taxation", Journal of Public Economics 20, 77-88.

[27] Persson, M. (1995), "Why are taxes so high in egalitarian societies?", Scandinavian Journal of Economics 97, 569-580.

[28] Rae, J. (1834), The new principles of political economy, edited by C. H. Mixter. Reprinted as The sociological theory of capital, New York: Macmillan, 1905.

[29] Runciman, W. G. (1966), Relative deprivation and social justice, Routledge and Kegan Paul, London.

[30] Schor, J. (1998), The overspent American: upscaling, downshifting and the new consumer, Basic Books.

[31] Scitovsky, T. (1976), The joyless economy: an inquiry into human satisfaction and consumer dissatisfaction, Oxford University Press.

[32] Seidman, L. S. (1987), "Relativity and efficient taxation", Southern Economic Journal 54, 463-474.

[33] Solnick, S. J. and D. Hemenway (2005), "Are positional concerns stronger in some domains than in others?", American Economic Review, Papers and Proceedings 45, 147-151.

[34] Stiglitz, J. E. (1982), "Self-selection and Pareto-efficient taxation", Journal of Public Economics 17, 213-240.

[35] Veblen, T. (1899), The theory of the leisure class, New York: Modern Library.

[36] Wicksteed, P. (1933), The common sense of political economy, London: George Routledge \& Sons. 
WORKING PAPERS*

Editor: Nils Gottfries

2007:22 Fredrik Johansson, How to Adjust for Nonignorable Nonresponse: Calibration, Heckit or FIML? 25pp.

2007:23 Henry Ohlsson, The legacy of the Swedish gift and inheritance tax, 18842004. 25pp.

2007:24 Ranjula Bali Swain and Fan Yang Wallentin, DOES MICROFINANCE EMPOWER WOMEN? Evidence from Self Help Groups in India. 26pp.

2007:25 Bertil Holmlund and Martin Söderström, Estimating Income Responses to Tax Changes: A Dynamic Panel Data Approach. 34pp.

2007:26 N. Anders Klevmarken, Simulating the future of the Swedish baby-boom generations. 60pp.

2007:27 Olof Åslund and Oskar Nordström Skans, How to Measure Segregation Conditional on the Distribution of Covariates. 17pp.

2007:28 Che-Yuan Liang, Is There an Incumbency Advantage or a Cost of Ruling in Proportional Election Systems? 20pp.

2007:29 Stefan Eriksson and Jonas Lagerström, Detecting discrimination in the hiring process: Evidence from an Internet-based search channel. 31pp.

2007:30 Helge Berger and Pär Österholm, Does Money Growth Granger-Cause Inflation in the Euro Area? Evidence from Out-of-Sample Forecasts Using Bayesian VARs. 32pp.

2007:31 Ranjula Bali Swain and Maria Floro, Effect of Microfinance on Vulnerability, Poverty and Risk in Low Income Households. 35pp.

2008:1 Mikael Carlsson, Johan Lyhagen and Pär Österholm, Testing for Purchasing Power Parity in Cointegrated Panels. 20pp.

2008:2 Che-Yuan Liang, Collective Lobbying in Politics: Theory and Empirical Evidence from Sweden. 37pp.

2008:3 Spencer Dale, Athanasios Orphanides and Pär Österholm, Imperfect Central Bank Communication: Information versus Distraction. 33pp.

2008:4 Matz Dahlberg and Eva Mörk, Is there an election cycle in public employment? Separating time effects from election year effects. 29pp.

2008:5 Ranjula Bali Swain and Adel Varghese, Does Self Help Group Participation Lead to Asset Creation. 25pp.

\footnotetext{
* A list of papers in this series from earlier years will be sent on request by the department.
} 
2008:6 Niklas Bengtsson, Do Protestant Aid Organizations Aid Protestants Only? 28pp.

2008:7 Mikael Elinder, Henrik Jordahl and Panu Poutvaara, Selfish and Prospective Theory and Evidence of Pocketbook Voting. 31pp.

2008:8 Erik Glans, The effect of changes in the replacement rate on partial retirement in Sweden. 30pp.

2008:9 Erik Glans, Retirement patterns during the Swedish pension reform. 44pp.

2008:10 Stefan Eriksson and Jonas Lageström, The Labor Market Consequences of Gender Differences in Job Search. 16pp.

2008:11 Ranjula Bali Swain and Fan Yang Wallentin, Economic or Non-Economic Factors - What Empowers Women?. 34pp.

2008:12 Matz Dahlberg, Heléne Lundqvist and Eva Mörk, Intergovernmental Grants and Bureaucratic Power. 34pp.

2008:13 Matz Dahlberg, Kajsa Johansson and Eva Mörk, On mandatory activation of welfare receivers. 39pp.

2008:14 Magnus Gustavsson, A Longitudinal Analysis of Within-Education-Group Earnings Inequality. 26pp.

2008:15 Henrique S. Basso, Delegation, Time Inconsistency and Sustainable Equilibrium. 24pp.

2008:16 Sören Blomquist and Håkan Selin, Hourly Wage Rate and Taxable Labor Income Responsiveness to Changes in Marginal Tax Rates. $31 \mathrm{pp}$.

2008:17 Jie Chen and Aiyong Zhu, The relationship between housing investment and economic growth in China : A panel analysis using quarterly provincial data. 26pp.

2009:1 Per Engström, Patrik Hesselius and Bertil Holmlund, Vacancy Referrals, Job Search, and the Duration of Unemployment: A Randomized Experiment. $25 \mathrm{pp}$.

2009:2 Chuan-Zhong Li and Gunnar Isacsson, Valuing urban accessibility and air quality in Sweden: A regional welfare analysis. 24pp.

2009:3 Luca Micheletto, Optimal nonlinear redistributive taxation and public good provision in an economy with Veblen effects. $26 \mathrm{pp}$.

See also working papers published by the Office of Labour Market Policy Evaluation http://www.ifau.se/ 